\title{
Cone metric spaces with Banach algebras and fixed point theorems of generalized Lipschitz mappings
}

Hao Liu ${ }^{1}$ and Shaoyuan $\mathrm{Xu}^{2 *}$

\section{"Correspondence:}

xushaoyuan@126.com

${ }^{2}$ Department of Mathematics and

Statistics, Hanshan Normal

University, Chaozhou, 521041, China

Full list of author information is

available at the end of the article

\begin{abstract}
In this paper we introduce the concept of cone metric spaces with Banach algebras, replacing Banach spaces by Banach algebras as the underlying spaces of cone metric spaces. With this modification, we shall prove some fixed point theorems of generalized Lipschitz mappings with weaker conditions on generalized Lipschitz constants. An example shows that our main results concerning the fixed point theorems in the setting of cone metric spaces with Banach algebras are more useful than the standard results in cone metric spaces presented in the literature.
\end{abstract}

MSC: $54 \mathrm{H} 25 ; 47 \mathrm{H} 10$

Keywords: cone metric spaces with Banach algebras; fixed point theorems; generalized Lipschitz conditions

\section{Introduction}

Cone metric spaces were introduced by Huang and Zhang as a generalization of metric spaces in [1]. The distance $d(x, y)$ of two elements $x$ and $y$ in a cone metric space $X$ is defined to be a vector in an ordered Banach space $E$, and a mapping $T: X \rightarrow X$ is said to be contractive if there is a constant $k \in[0,1)$ such that

$$
d(T x, T y) \leq k d(x, y), \quad x, y \in X .
$$

The right-hand side of inequality (1) is the vector as the result of the operation of scalar multiplication in cone metric spaces. In [1], the authors proved that there exists a unique fixed point for contractive mappings in complete cone metric spaces. Recently, scholars obtained that any cone metric space $(X, d)$ is equivalent to the usual metric space $\left(X, d^{*}\right)$, where the real-valued metric function $d^{*}$ is defined by a nonlinear scalarization function $\xi_{e}$. See, for instance, [2, 3] and [4]. In particular, for each contractive mapping $T$ in $(X, d)$ satisfying $(1)$, one can get

$$
d^{*}(T x, T y) \leq k d^{*}(x, y), \quad x, y \in X,
$$

which implies that cone metric spaces are a special case of classical metric spaces. After that, some other interesting generalizations were developed. See, for instance, [5].

In this paper, we replace the Banach space $E$ by a Banach algebra $A$ and obtain the concept of cone metric spaces with Banach algebras. In this way, we shall prove some fixed

○2013 Liu and Xu; licensee Springer. This is an Open Access article distributed under the terms of the Creative Commons Attribution License (http://creativecommons.org/licenses/by/2.0), which permits unrestricted use, distribution, and reproduction in any medium, provided the original work is properly cited. 
point theorems of generalized Lipschitz mappings with weaker and natural conditions on the Lipschitz constant $k$. Our results generalize metric spaces and reveal the fact that the essential conditions on the contraction constant $k$ are neither order relations nor norm relations, but spectrum radius.

Let $A$ always be a real Banach algebra. That is, $A$ is a real Banach space in which an operation of multiplication is defined, subject to the following properties (for all $x, y, z \in A$, $\alpha \in \mathbb{R})$ :

1. $(x y) z=x(y z)$;

2. $x(y+z)=x y+x z$ and $(x+y) z=x z+y z$;

3. $\alpha(x y)=(\alpha x) y=x(\alpha y)$;

4. $\|x y\| \leq\|x\|\|y\|$.

In this paper, we shall assume that a Banach algebra has a unit (i.e., a multiplicative identity) $e$ such that $e x=x e=x$ for all $x \in A$. An element $x \in A$ is said to be invertible if there is an inverse element $y \in A$ such that $x y=y x=e$. The inverse of $x$ is denoted by $x^{-1}$. For more details, we refer to [6].

The following proposition is well known (see [6]).

Proposition 1.1 Let $A$ be a Banach algebra with a unit e, and $x \in A$. If the spectral radius $\rho(x)$ of $x$ is less than 1 , i.e.,

$$
\rho(x)=\lim _{n \rightarrow \infty}\left\|x^{n}\right\|^{\frac{1}{n}}=\inf _{n \geq 1}\left\|x^{n}\right\|^{\frac{1}{n}}<1,
$$

then $e-x$ is invertible. Actually,

$$
(e-x)^{-1}=\sum_{i=0}^{\infty} x^{i}
$$

A subset $P$ of $A$ is called a cone if

1. $P$ is non-empty closed and $\{0, e\} \subset P$;

2. $\alpha P+\beta P \subset P$ for all non-negative real numbers $\alpha, \beta$;

3. $P^{2}=P P \subset P$;

4. $P \cap(-P)=\{0\}$.

For a given cone $P \subset A$, we can define a partial ordering $\leq$ with respect to $P$ by $x \leq y$ if and only if $y-x \in P$. $x \supsetneqq y$ will stand for $x \leq y$ and $x \neq y$. While $x<y$ will stand for $y-x \in \operatorname{int} P$, where int $P$ denotes the interior of $\mathrm{P}$.

The cone $P$ is called normal if there is a number $M>0$ such that for all $x, y \in A$,

$$
0 \leq x \leq y \quad \Rightarrow \quad\|x\| \leq M\|y\| .
$$

The least positive number satisfying the above is called the normal constant of $P$ [1].

In the following we always assume that $P$ is a cone in $A$ with int $P \neq \emptyset$ and $\leq$ is the partial ordering with respect to $P$.

Definition 1.1 (See [1]) Let $X$ be a non-empty set. Suppose that the mapping $d: X \times X \rightarrow$ $A$ satisfies

1. $0 \leq d(x, y)$ for all $x, y \in X$ and $d(x, y)=0$ if and only if $x=y$; 
2. $d(x, y)=d(y, x)$ for all $x, y \in X$;

3. $d(x, y) \leq d(x, z)+d(z, x)$ for all $x, y, z \in X$.

Then $d$ is called a cone metric on $X$, and $(X, d)$ is called a cone metric space (with a Banach algebra $A$ ).

We present some examples in the following.

Example 1.1 Let $A=M_{n}(\mathbb{R})=\left\{a=\left(a_{i j}\right)_{n \times n} \mid a_{i j} \in \mathbb{R}\right.$ for all $\left.1 \leq i, j \leq n\right\}$ be the algebra of all $n$-square real matrices, and define the norm

$$
\|a\|=\sum_{1 \leq i, j \leq n}\left|a_{i j}\right|
$$

Then $A$ is a real Banach algebra with the unit $e$, the identity matrix.

Let $P=\left\{a \in A \mid a_{i j} \geq 0\right.$ for all $\left.1 \leq i, j \leq n\right\}$. Then $P \subset A$ is a normal cone with a normal constant $M=1$.

Let $X=M_{n}(\mathbb{R})$, and define the metric $d: X \times X \rightarrow A$ by

$$
d(x, y)=d\left(\left(x_{i j}\right)_{n \times n},\left(y_{i j}\right)_{n \times n}\right)=\left(\left|x_{i j}-y_{i j}\right|\right)_{n \times n} \in A .
$$

Then $(X, d)$ is a cone metric space with a Banach algebra $A$.

Example 1.2 Let $A$ be the Banach space $C(K)$ of all continuous real-valued functions on a compact Hausdorff topological space $K$, with multiplication defined pointwise. Then $A$ is a Banach algebra, and the constant function $f(t)=1$ is the unit of $A$.

Let $P=\{f \in A \mid f(t) \geq 0$ for all $t \in K\}$. Then $P \subset A$ is a normal cone with a normal constant $M=1$.

Let $X=C(K)$ with the metric mapping $d: X \times X \rightarrow A$ defined by

$$
d(f, g)=|f(t)-g(t)|, \quad \text { where } t \in K \text {. }
$$

Then $(X, d)$ is a cone metric space with a Banach algebra $A$.

Example 1.3 Let $A=\ell^{1}=\left\{a=\left(a_{n}\right)_{n \geq 0}\left|\sum_{n=0}^{\infty}\right| a_{n} \mid<\infty\right\}$ with convolution as multiplication:

$$
a b=\left(a_{n}\right)_{n \geq 0}\left(b_{n}\right)_{n \geq 0}=\left(\sum_{i+j=n} a_{i} b_{j}\right)_{n \geq 0} .
$$

Thus $A$ is a Banach algebra. The unit $e$ is $(1,0,0, \ldots)$.

Let $P=\left\{a=\left(a_{n}\right)_{n \geq 0} \in A \mid a_{n} \geq 0\right.$ for all $\left.n \geq 0\right\}$, which is a normal cone in $A$.

And let $X=\ell^{1}$ with the metric $d: X \times X \rightarrow A$ defined by

$$
d(x, y)=d\left(\left(x_{n}\right)_{n \geq 0},\left(y_{n}\right)_{n \geq 0}\right)=\left(\left|x_{n}-y_{n}\right|\right)_{n \geq 0} .
$$

Then $(X, d)$ is a cone metric space with $A$. 
Definition 1.2 (See [1]) Let $(X, d)$ be a cone metric space, $x \in X$ and $\left\{x_{n}\right\}$ a sequence in $X$.

Then

1. $\left\{x_{n}\right\}$ converges to $x$ whenever for each $c \in A$ with $0<c$, there is a natural number $N$ such that $d\left(x_{n}, x\right)<c$ for all $n \geq N$. We denote this by $\lim _{n \rightarrow \infty} x_{n}=x$ or $x_{n} \rightarrow x$.

2. $\left\{x_{n}\right\}$ is a Cauchy sequence whenever for each $c \in A$ with $0<c$, there is a natural number $N$ such that $d\left(x_{n}, x_{m}\right)<c$ for all $n, m \geq N$.

3. $(X, d)$ is a complete cone metric space if every Cauchy sequence is convergent.

Finally, we shall appeal to the following lemmas in the sequel [1].

Lemma 1.1 Let $(X, d)$ be a cone metric space, $P$ be a normal cone with a normal constant $M$. Let $\left\{x_{n}\right\}$ be a sequence in $X$. Then $\left\{x_{n}\right\}$ converges to $x$ if and only if $d\left(x_{n}, x\right) \rightarrow 0(n \rightarrow \infty)$.

Lemma 1.2 Let $(X, d)$ be a cone metric space, $P$ be a normal cone with a normal constant $M$. Let $\left\{x_{n}\right\}$ be a sequence in $X$. Then $\left\{x_{n}\right\}$ is a Cauchy sequence if and only if $d\left(x_{n}, x_{m}\right) \rightarrow 0$ $(n, m \rightarrow \infty)$.

\section{Main results}

In this section we shall prove some fixed point theorems of generalized Lipschitz mappings in the setting of cone metric spaces with Banach algebras.

Theorem 2.1 Let $(X, d)$ be a complete cone metric space and $P$ be a normal cone with a normal constant $M$. Suppose that the mapping $T: X \rightarrow X$ satisfies the generalized Lipschitz condition

$$
d(T x, T y) \leq k d(x, y), \quad \text { for all } x, y \in X,
$$

where $k \in P$ with $\rho(k)<1$. Then $T$ has a unique fixed point in $X$. And for any $x \in X$, iterative sequence $\left\{T^{n} x\right\}$ converges to the fixed point.

Proof Choose $x_{0} \in X$ and set $x_{n}=T^{n} x, n \geq 1$. We have

$$
d\left(x_{n+1}, x_{n}\right) \leq k d\left(x_{n}, x_{n-1}\right) \leq \cdots \leq k^{n} d\left(x_{1}, x_{0}\right) .
$$

Thus, for $n<m$,

$$
\begin{aligned}
d\left(x_{n}, x_{m}\right) & \leq d\left(x_{n}, x_{n+1}\right)+\cdots+d\left(x_{m-1}, x_{m}\right) \\
& \leq\left(k^{n}+\cdots+k^{m-1}\right) d\left(x_{1}, x_{0}\right) \\
& =\left(e+k+\cdots+k^{m-n-1}\right) k^{n} d\left(x_{1}, x_{0}\right) \\
& \leq\left(\sum_{i=0}^{\infty} k^{i}\right) k^{n} d\left(x_{1}, x_{0}\right) \\
& =(e-k)^{-1} k^{n} d\left(x_{1}, x_{0}\right) .
\end{aligned}
$$

Since $P$ is normal with a normal constant $M$, and note that $\left\|k^{n}\right\| \rightarrow 0(n \rightarrow \infty)$, we have

$$
\left\|d\left(x_{n}, x_{m}\right)\right\| \leq M\left\|(e-k)^{-1}\right\|\left\|k^{n}\right\|\left\|d\left(x_{1}, x_{0}\right)\right\| \rightarrow 0 \quad(n \rightarrow \infty) .
$$


Hence $\left\{x_{n}\right\}$ is a Cauchy sequence. By the completeness of $X$, there exists $x^{*} \in X$ such that $x_{n} \rightarrow x^{*}(n \rightarrow \infty)$. Furthermore, one has

$$
d\left(T x^{*}, x^{*}\right) \leq d\left(T x^{*}, T x_{n}\right)+d\left(T x_{n}, x^{*}\right) \leq k d\left(x^{*}, x_{n}\right)+d\left(x_{n+1}, x^{*}\right),
$$

and consequently,

$$
\left\|d\left(T x^{*}, x^{*}\right)\right\| \leq M\left(\|k\|\left\|d\left(x^{*}, x_{n}\right)\right\|+\left\|d\left(x_{n+1}, x^{*}\right)\right\|\right) \rightarrow 0 \quad(n \rightarrow \infty) .
$$

Hence $\left\|d\left(T x^{*}, x^{*}\right)\right\|=0$. This implies $T x^{*}=x^{*}$. So, $x^{*}$ is a fixed point of $T$.

Now if $y^{*}$ is another fixed point of $T$, then

$$
d\left(x^{*}, y^{*}\right)=d\left(T x^{*}, T y^{*}\right) \leq k d\left(x^{*}, y^{*}\right) .
$$

That is,

$$
(e-k) d\left(x^{*}, y^{*}\right) \leq 0 .
$$

Multiplying both sides above by

$$
(e-k)^{-1}=\sum_{i=0}^{\infty} k^{i} \geq 0
$$

we get $d\left(x^{*}, y^{*}\right) \leq 0$. Thus $d\left(x^{*}, y^{*}\right)=0$, which implies that $x^{*}=y^{*}$, a contradiction. Hence, the fixed point is unique.

Remark 2.1 Note that in Theorem 2.1 we only suppose that the spectral radius of $k$ is less than 1 , neither $k<e$ nor $\|k\|<1$ assumed. This is a vital improvement. In fact, the condition $\rho(k)<1$ is weaker than that $\|k\|<1$, as is illustrated by Example 2.1 in the sequel. The improvement of the condition about the generalized Lipschitz constant $k$ shows that it is meaningful to introduce the concepts of cone metric spaces with Banach algebras and a generalized Lipschitz condition.

Theorem 2.2 Let $(X, d)$ be a complete cone metric space, $P$ be a normal cone with a normal constant M. Suppose that the mapping $T: X \rightarrow X$ satisfies the generalized Lipschitz condition

$$
d(T x, T y) \leq k(d(T x, y)+d(T y, x)), \quad \text { for all } x, y \in X,
$$

where $k \in P$ with $\rho(k)<\frac{1}{2}$. Then $T$ has a unique fixed point in $X$. And for any $x \in X$, iterative sequence $\left\{T^{n} x\right\}$ converges to the fixed point.

Proof Choose $x_{0} \in X$, and set $x_{n}=T^{n} x, n \geq 1$. We have

$$
\begin{aligned}
d\left(x_{n+1}, x_{n}\right) & =d\left(T x_{n}, T x_{n-1}\right) \\
& \leq k\left(d\left(T x_{n}, x_{n-1}\right)+d\left(T x_{n-1}, x_{n}\right)\right) \\
& \leq k\left(d\left(x_{n+1}, x_{n}\right)+d\left(x_{n}, x_{n-1}\right)\right) .
\end{aligned}
$$


That is,

$$
d\left(x_{n+1}, x_{n}\right) \leq(e-k)^{-1} k d\left(x_{n}, x_{n-1}\right)
$$

We shall prove that

$$
\lim _{n \rightarrow \infty}\left\|\left((e-k)^{-1} k\right)^{n}\right\|^{\frac{1}{n}}<1
$$

which implies that $\left\{x_{n}\right\}$ is a Cauchy sequence by the proof of Theorem 2.1. Note that $(e-$ $k)^{-1}$ and $k$ commute.

Let $n$ be large enough such that

$$
\left\|k^{n+i}\right\|^{\frac{1}{n+i}} \leq \alpha, \quad \text { for all } i \geq 0
$$

where $\alpha \in \mathbb{R}$ such that $\lim _{n \rightarrow \infty}\left\|k^{n}\right\|^{\frac{1}{n}}<\alpha<\frac{1}{2}$.

Denote that

$$
(e-k)^{-n}=\left(\sum_{i=0}^{\infty} k^{i}\right)^{n}=\sum_{i=0}^{\infty} \beta_{i}^{(n)} k^{i}
$$

where $\beta_{i}^{(n)} \in \mathbb{R}, n, i \geq 0$. It is easy to see that $\beta_{i}^{(n)} \geq 0$ for all $n, i \geq 0$.

Then

$$
\begin{aligned}
\left\|\left((e-k)^{-1} k\right)^{n}\right\| & =\left\|(e-k)^{-n} k^{n}\right\|=\left\|\sum_{i=0}^{\infty} \beta_{i}^{(n)} k^{n+i}\right\| \\
& \leq \sum_{i=0}^{\infty} \beta_{i}^{(n)}\left\|k^{n+i}\right\| \leq \sum_{i=0}^{\infty} \beta_{i}^{(n)} \alpha^{n+i} \\
& =\alpha^{n}\left(\sum_{i=0}^{\infty} \alpha^{i}\right)^{n}=\left(\frac{\alpha}{1-\alpha}\right)^{n} .
\end{aligned}
$$

Hence

$$
\lim _{n \rightarrow \infty}\left\|\left((e-k)^{-1} k\right)^{n}\right\|^{\frac{1}{n}} \leq \frac{\alpha}{1-\alpha}<1,
$$

and $\left\{x_{n}\right\}$ is a Cauchy sequence.

By the completeness of $X$, there is $x^{*} \in X$ such that $x_{n} \rightarrow x^{*}(n \rightarrow \infty)$. To verify $T x^{*}=x^{*}$, we have

$$
\begin{aligned}
d\left(T x^{*}, x^{*}\right) & \leq d\left(T x^{*}, T x_{n}\right)+d\left(T x_{n}, x^{*}\right) \\
& \leq k\left(d\left(T x^{*}, x_{n}\right)+d\left(T x_{n}, x^{*}\right)\right)+d\left(x_{n+1}, x^{*}\right) \\
& \leq k\left(d\left(T x^{*}, x^{*}\right)+d\left(x^{*}, x_{n}\right)+d\left(x_{n+1}, x^{*}\right)\right)+d\left(x_{n+1}, x^{*}\right) .
\end{aligned}
$$

That is,

$$
(e-k) d\left(T x^{*}, x^{*}\right) \leq k d\left(x^{*}, x_{n}\right)+(e+k) d\left(x^{*}, x_{n+1}\right) .
$$


By the normality of $P$, we have

$$
\left\|d\left(T x^{*}, x^{*}\right)\right\| \leq M\left\|(e-k)^{-1}\right\|\left(\|k\|\left\|d\left(x^{*}, x_{n}\right)\right\|+\|(e+k)\|\left\|d\left(x^{*}, x_{n+1}\right)\right\|\right) \rightarrow 0
$$

as $n \rightarrow \infty$. Hence $x^{*}$ is a fixed point of $T$.

Now if $y^{*}$ is another fixed point, then

$$
\begin{aligned}
d\left(x^{*}, y^{*}\right) & =d\left(T x^{*}, T y^{*}\right) \\
& \leq k\left(d\left(T x^{*}, y^{*}\right)+d\left(T y^{*}, x^{*}\right)\right) \\
& =2 k d\left(x^{*}, y^{*}\right) .
\end{aligned}
$$

Thus

$$
d\left(x^{*}, y^{*}\right) \leq(2 k)^{n} d\left(x^{*}, y^{*}\right)
$$

for any $n \geq 1$. Since $\lim _{n \rightarrow \infty}\left\|(2 k)^{n}\right\|=0$, we have

$$
\left\|d\left(x^{*}, y^{*}\right)\right\| \leq M\left\|(2 k)^{n}\right\|\left\|d\left(x^{*}, y^{*}\right)\right\| \rightarrow 0 \quad(n \rightarrow \infty) .
$$

Then $d\left(x^{*}, y^{*}\right)=0$, which implies that $x^{*}=y^{*}$, a contradiction. Hence, the fixed point is unique.

Theorem 2.3 Let $(X, d)$ be a complete cone metric space, $P$ be a normal cone with a normal constant $M$. Suppose that the mapping $T: X \rightarrow X$ satisfies the generalized Lipschitz condition

$$
d(T x, T y) \leq k(d(T x, x)+d(T y, y)) \quad \text { for all } x, y \in X,
$$

where $k \in P$ with $\rho(k)<\frac{1}{2}$. Then $T$ has a unique fixed point in $X$. And for any $x \in X$, the iterative sequence $\left\{T^{n} x\right\}$ converges to the fixed point.

Proof Choose $x_{0} \in X$, and set $x_{n}=T^{n} x, n \geq 1$. We have

$$
\begin{aligned}
d\left(x_{n+1}, x_{n}\right) & =d\left(T x_{n}, T x_{n-1}\right) \\
& \leq k\left(d\left(T x_{n}, x_{n}\right)+d\left(T x_{n-1}, x_{n-1}\right)\right) \\
& =k\left(d\left(x_{n+1}, x_{n}\right)+d\left(x_{n}, x_{n-1}\right)\right) .
\end{aligned}
$$

That is,

$$
d\left(x_{n+1}, x_{n}\right) \leq(e-k)^{-1} k d\left(x_{n}, x_{n-1}\right) .
$$

As is shown in the proof of Theorem 2.2, it follows that $\left\{x_{n}\right\}$ is a Cauchy sequence, and, by the completeness of $X$, the limit of $x_{n}$ exists and is denoted by $x^{*}$.

To see that $x^{*}$ is a fixed point of $T$, we have

$$
d\left(T x^{*}, x^{*}\right) \leq d\left(T x^{*}, T x_{n}\right)+d\left(T x_{n}, x^{*}\right) \leq k\left(d\left(T x^{*}, x^{*}\right)+d\left(T x_{n}, x_{n}\right)\right)+d\left(x_{n+1}, x^{*}\right) .
$$


Therefore,

$$
d\left(T x^{*}, x^{*}\right) \leq(e-k)^{-1}\left(k d\left(x_{n+1}, x_{n}\right)+d\left(x_{n+1}, x^{*}\right)\right),
$$

and

$$
\left\|d\left(T x^{*}, x^{*}\right)\right\| \leq M\left\|(e-k)^{-1}\right\|\left(\|k\|\left\|d\left(x_{n+1}, x_{n}\right)\right\|+\left\|d\left(x_{n+1}, x^{*}\right)\right\|\right) \rightarrow 0
$$

as $n \rightarrow \infty$.

Now if $y^{*}$ is another fixed point of $T$, then

$$
d\left(x^{*}, y^{*}\right)=d\left(T x^{*}, T y^{*}\right) \leq k\left(d\left(T x^{*}, x^{*}\right)+d\left(T y^{*}, y^{*}\right)\right)=0,
$$

which implies that $x^{*}=y^{*}$, a contradiction. Hence, the fixed point is unique.

We conclude the paper with an example.

Example 2.1 Let $A=\mathbb{R}^{2}$. For each $\left(x_{1}, x_{2}\right) \in A,\left\|\left(x_{1}, x_{2}\right)\right\|=\left|x_{1}\right|+\left|x_{2}\right|$. The multiplication is defined by

$$
x y=\left(x_{1}, x_{2}\right)\left(y_{1}, y_{2}\right)=\left(x_{1} y_{1}, x_{1} y_{2}+x_{2} y_{1}\right) .
$$

Then $A$ is a Banach algebra with unit $e=(1,0)$.

Let $P=\left\{\left(x_{1}, x_{2}\right) \in \mathbb{R}^{2} \mid x_{1}, x_{2} \geq 0\right\}$. Then $P$ is normal with a normal constant $M=1$.

Let $X=\mathbb{R}^{2}$ and the metric $d$ be defined by

$$
d(x, y)=d\left(\left(x_{1}, x_{2}\right),\left(y_{1}, y_{2}\right)\right)=\left(\left|x_{1}-y_{1}\right|,\left|x_{2}-y_{2}\right|\right) \in P .
$$

Then $(X, d)$ is a complete cone metric space.

Now define the mapping $T: X \rightarrow X$ by

$$
T\left(x_{1}, x_{2}\right)=\left(\log \left(2+\left|x_{1}\right|\right), \arctan \left(3+\left|x_{2}\right|\right)+\alpha x_{1}\right),
$$

where $\alpha$ can be any large positive real number.

From Lagrange mean value theorem, we have

$$
\begin{aligned}
d\left(T\left(x_{1}, x_{2}\right), T\left(y_{1}, y_{2}\right)\right) & \leq\left(\frac{1}{2}\left|x_{1}-y_{1}\right|, \frac{1}{10}\left|x_{2}-y_{2}\right|+\alpha\left|x_{1}-y_{1}\right|\right) \\
& \leq\left(\frac{1}{2}, \alpha\right) d\left(\left(x_{1}, x_{2}\right),\left(y_{1}, y_{2}\right)\right),
\end{aligned}
$$

and

$$
\left\|\left(\frac{1}{2}, \alpha\right)^{n}\right\|^{\frac{1}{n}}=\left\|\left(\left(\frac{1}{2}\right)^{n}, \alpha n\left(\frac{1}{2}\right)^{n-1}\right)\right\|^{\frac{1}{n}} \rightarrow \frac{1}{2}<1 \quad(n \rightarrow \infty) .
$$

Then, by Theorem 2.1, $T$ has a unique fixed point in $X$. 
Remark 2.2 In Example 2.1 above, we see that $\left(\frac{1}{2}, \alpha\right) \nless(1,0)=e$ and $\left\|\left(\frac{1}{2}, \alpha\right)\right\|=\frac{1+2 \alpha}{2}>1$ (for $\alpha>1$ ). Moreover, $T$ is not a contractive mapping in the Euclidean metric on $X$. Hence, Example 2.1 shows that the main results in this paper are more powerful than the standard results of cone metric spaces presented in the literature.

Remark 2.3 Example 2.1 also shows that one is unable to conclude that the cone metric space $(X, d)$ with a Banach algebra $A$ defined above is equivalent to the metric space $\left(X, d^{*}\right)$, where the metric $d^{*}$ is defined by $d^{*}=\xi_{e} \circ d$; here, the nonlinear scalarization function $\xi_{e}: A \rightarrow \mathbb{R}(e \in \operatorname{int} P)$ is defined by

$$
\xi_{e}(y)=\inf \{r \in \mathbb{R}: y \in r e-P\}
$$

See $[2,3]$ and [4] for more details. In fact, under this situation, we have

$$
\text { int } P=\left\{\left(x_{1}, x_{2}\right) \in \mathbb{R}^{2} \mid x_{1}, x_{2}>0\right\}
$$

For $e=\left(e_{1}, e_{2}\right) \in \operatorname{int} P$ and $a=\left(a_{1}, a_{2}\right) \in A$,

$$
\begin{aligned}
\xi_{e}(a) & =\xi_{e}\left(\left(a_{1}, a_{2}\right)\right) \\
& =\inf \left\{t \in \mathbb{R} \mid\left(a_{1}, a_{2}\right) \leq t\left(e_{1}, e_{2}\right)\right\} \\
& =\max \left\{\frac{a_{1}}{e_{1}}, \frac{a_{2}}{e_{2}}\right\},
\end{aligned}
$$

and for $x, y \in X$,

$$
d^{*}(x, y)=\left(\xi_{e} \circ d\right)(x, y)=\max \left\{\frac{\left|x_{1}-y_{1}\right|}{e_{1}}, \frac{\left|x_{2}-y_{2}\right|}{e_{2}}\right\} .
$$

Now let the mapping $T: X \rightarrow X$ be defined as in (3) with $\alpha>\frac{e_{2}}{e_{1}}$, and consider $x=(1,0)$, $y=(0,0)$. We have

$$
d^{*}(T x, T y)=\max \left\{\frac{\log 3-\log 2}{e_{1}}, \frac{\alpha}{e_{2}}\right\} \geq \frac{\alpha}{e_{2}}>\frac{1}{e_{1}}=d^{*}(x, y),
$$

which implies that $T$ is not a contraction in the metric space $\left(X, d^{*}\right)$. This shows that one is unable to prove that Theorem 2.1 above is a consequence of the corresponding results in metric spaces by means of the methods presented in the literature.

\section{Competing interests}

The authors declare that they have no competing interests.

Authors' contributions

Both authors contributed equally and significantly in writing this paper. Both authors read and approved the final manuscript.

\section{Author details}

${ }^{1}$ School of Mathematics and Statistics, Hubei Normal University, Huangshi, 435002, China. ${ }^{2}$ Department of Mathematics and Statistics, Hanshan Normal University, Chaozhou, 521041, China. 


\section{Acknowledgements}

The authors are grateful to the referees and the editors for valuable comments and suggestions, which have improved the original manuscript greatly. The research is partially supported by the PhD Start-up Fund of Hanshan Normal University, Guangdong Province, China (No. QD20110920).

Received: 28 July 2013 Accepted: 29 October 2013 Published: 25 Nov 2013

\section{References}

1. Long-Guang, $\mathrm{H}$, Xian, Z: Cone metric spaces and fixed point theorems of contractive mappings. J. Math. Anal. Appl. $332,1468-1476(2007)$

2. Arandelović, ID, Kečkić, DJ: TVS-cone metric spaces as a special case of metric spaces (2012) (preprint). arXiv:1202.5930

3. Çakallı, H, Sönmez, A, Genç, Ç: On an equivalence of topological vector space valued cone metric spaces and metric spaces. Appl. Math. Lett. 25, 429-433 (2012)

4. Du, WS: A note on cone metric fixed point theory and its equivalence. Nonlinear Anal. 72(5), 2259-2261 (2010)

5. Abbas, M, Rajić, VĆ, Nazir, T, Radenović, S: Common fixed point of mappings satisfying rational inequalities in ordered complex valued generalized metric spaces. Afr. Math. (2013). doi:10.1007/s13370-013-0185-z

6. Rudin, W: Functional Analysis, 2nd edn. McGraw-Hill, New York (1991)

10.1186/1687-1812-2013-320

Cite this article as: Liu and Xu: Cone metric spaces with Banach algebras and fixed point theorems of generalized

Lipschitz mappings. Fixed Point Theory and Applications 2013, 2013:320

\section{Submit your manuscript to a SpringerOpen ${ }^{\circ}$ journal and benefit from:}

- Convenient online submission

- Rigorous peer review

- Immediate publication on acceptance

- Open access: articles freely available online

- High visibility within the field

- Retaining the copyright to your article 